$67^{\text {th }}$ International Astronautical Congress 2016, Guadalajara, Mexico. Copyright (C2016 by the IAF. All rights reserved.

IAC- $16, \mathrm{~A} 3,4,3$

\title{
ROSETTA LANDER - PHILAE: OPERATIONS ON COMET 67P/CHURYUMOV-GERASIMENKO, ANALYSIS OF WAKE-UP ACTIVITIES AND FINAL STATE
}

\author{
Stephan Ulamec \\ Deutsches Zentrum für Luft- und Raumfahrt e.V. (DLR), Germany, stephan.ulamec@dlr.de \\ Jens Biele \\ Deutsches Zentrum für Luft- und Raumfahrt e.V. (DLR), Germany, jens.biele@dlr.de \\ Cinzia Fantinati \\ Deutsches Zentrum für Luft- und Raumfahrt e.V. (DLR), Germany, cinzia.fantinati@dlr.de \\ Valentina Lommatsch \\ Deutsches Zentrum für Luft- und Raumfahrt e.V. (DLR), Germany, valentina.lommatsch@dlr.de \\ Koen Geurts \\ Deutsches Zentrum für Luft- und Raumfahrt e.V. (DLR), Germany, koen.geurts@dlr.de \\ Michael Maibaum \\ Deutsches Zentrum für Luft- und Raumfahrt e.V. (DLR), Germany, michael.maibaum@dlr.de \\ Cedric Delmas \\ Centre National d'Etudes Spatiales (CNES), France, cedric.delmas@cnes.fr \\ Eric Jurado \\ Centre National d'Etudes Spatiales (CNES), France, Eric.Jurado@cnes.fr \\ Holger Sierks \\ Max Planck Institute (MPS), Germany, sierks@mps.mpg.de \\ Laurence O'Rourke \\ European Space Agency (ESA), Spain, Laurence.O'Rourke@esa.int \\ Cecilia Tubiana \\ Max Planck Institute (MPS), Germany, tubiana@mps.mpg.de \\ Carsten Güttler \\ Max Planck Institute (MPS), Germany, guettlerc@mps.mpg.de
}

Philae, a comet Lander, part of the ESA Rosetta mission successfully landed on comet 67P/ChuryumovGerasimenko on November $12^{\text {th }}$, 2014. After several (unplanned) bounces it performed a First Scientific Sequence (FSS), based on the energy stored in it's on board batteries. All ten instruments of the Philae payload have been operated at least once. Due to the fact that the original landing site was poorly illuminated, Philae went into hibernation on November $15^{\text {th }}$, but signals from the Lander were received again in June and July 2015. However, various attempts to re-establish reliable and stable communications links, failed.

Analysis of the data gained during FSS, and during the contacts in June and July 2015 allows conclusions on the state of Philae. By now, images from the OSIRIS camera aboard the Rosetta Orbiter have allowed the identification of the exact position of Philae and its attitude, relative to the local surface terrain. The paper also gives an overview of the implications of Philae results for future engineering comet models, required particularly for the design of in-situ (landing) or sample return missions.

Rosetta is an ESA mission with contributions from its member states and NASA.

Rosetta's Philae Lander is provided by a consortium led by DLR, MPS, CNES and ASI with additional contributions from Hungary, UK, Finland, Ireland and Austria.

\section{INTRODUCTION}

Rosetta is a Cornerstone Mission of the ESA Horizon 2000 programme [1]. In August 2014 it did rendezvous with comet $67 \mathrm{P} /$ Churyumov-Gerasimenko (CG) after a 10 year cruise. Both its nucleus and coma have been studied in detail. The mission is dramatically improving our understanding of the formation and evolution of the Solar System as well as the origin of life by investigating a comet both from orbit as well as 
with the Lander, Philae, in-situ, on the surface of the nucleus.

Observations with the instruments aboard the main spacecraft allowed the selection of a landing site for Philae and the preparation of the actual landing sequence [2]. Philae was separated from the Rosetta main spacecraft on November $12^{\text {th }}, 2014$ and touched the comet surface after seven hours of descent. However, the lander bounced off again and only came to rest after a leap of about 2 hours, approximately one kilometre from the originally targeted site [3]. Philae was operational for almost 64 hours after separation and provided unique information from the surface of the comet. All ten instruments aboard could be operated at least once. First scientific results have been published e.g. in [4].

Philae is operated by the Lander Control Centre (LCC) at the German Aerospace Center, DLR, in Cologne and the Science Operations and Navigation Centre (SONC) at the Centre national d'études spatiales, CNES, in Toulouse via the Rosetta Mission Operations Center, RMOC at the European Spacecraft Operations Centre (ESOC) in Darmstadt. The scientific lead is at the Max Planck Institute for Solar System Science in Göttingen, Germany, and the Institut d'Astrophysique Spatiale in Paris, France.

The Lander system has been provided by an international consortium (with partners in Germany (lead), France, Italy, Hungary, Finland, UK, Ireland and Austria) and supports a scientific payload of ten instruments with an even larger number of sensor elements [5].

\section{ON COMET OPERATIONS}

After injecting the Rosetta Orbiter into a dedicated delivery orbit [7], Philae was separated from the mothership on November $12^{\text {th }}, 08: 18$ UTC. The descent to the surface at site "Agilkia" lasted seven hours, touchdown was reported in the $\mathrm{H} / \mathrm{K}$ data at 15:34 UTC.

Unfortunately, as described in detail e.g. by Biele et al. [3], the lander bounced and only came to rest about 1 $\mathrm{km}$ distant to the originally anticipated site, at a location now referred to as "Abydos" at 17:31 UTC.

In the following a modified First Scientific Sequence (FSS) was performed on the comet surface. Operations are explained in detail by Ulamec et al. [8], science planning of Philae is discussed by Moussi et al. [9] and science planning of Rosetta, in support of Philae is described by Ashman et al. [10]. About $64 \mathrm{~h}$ after separation, the voltage of Philae's batteries dropped below the level to operate, and since Abydos was very badly illuminated, temperatures fell, the batteries could not be re-charged and the Lander went into hibernation. It was not clear when and if one would be able to receive signals from Philae again. Temperatures within the Lander probably fell well below $-100^{\circ} \mathrm{C}$, far out of the qualification limits.

But as the comet and Philae got closer and closer to the sun, on June $13^{\text {th }}$, signals from Philae were received again [8]. However, the hope to enter science operations again has not been fulfilled. Only eight times, signals from Philae were received on the Orbiter, the last ones on July $9^{\text {th }}, 2015$. Several attempts to reactivate (or command) the Lander, until early 2016, all failed.

The reason, why no stable and reproducible contact could be achieved is not fully clear. Possibilities are:

- Damage of electronics (transmitter/receiver system) e.g. due to cold temperatures during hibernation

- Movement (tilt) of Lander, leading to increased masking of the antenna pattern

- Dust deposition on the solar generator

An analysis of the radio links between Philae and Rosetta is given by Dudal and Loisel [11]. Attempts to re-activate the Lander are described by Geurts et al. [12].

\section{LANDER SEARCH}

Following the final touchdown of Philae on the surface of the comet in a location different to the Agilkia initial touchdown point, work immediately started to try to identify its final location.

The days during the FSS involved interactions between ESA Flight Dynamics and the CONSERT team to try to triangulate the location of the lander on the comet. This did indeed localise the new landing site to a region on the edge of the Hatmehit crater.

Further work in the months after landing by Consert led to them publishing a result [14] with the location of the lander defined within an ellipse measuring $16 \mathrm{x}$ $160 \mathrm{~m}$.

In the period from January 2015 through to March 2016, the distance from the comet was too great to allow high resolution images to be taken of the region within that ellipse thus although contact was established once more in June 2015, no images could be taken at that time.

It was in March 2016 when an active search campaign kicked off led by ESA and involving individuals from the ESA (SGS \& MOC), OSIRIS, the LCC (DLR) and the SONC (CNES) teams. This campaign focussed on two main possible lander 
candidates. The first was considered the prime candidate and it was identified by Lamy \& Faury from Laboratoire d'Astrophysique de Marseille early 2015. This candidate appeared to meet the various power \& RF \& visibility constraints linked to the actual data from the lander, also the images taken by the Philae CIVA cameras seemed to fit fairly well with surrounding landscape of this candidate as seen by OSIRIS. A second candidate was found outside of the Abydos region in a location much further south. This second candidate could only be deemed possible to be the lander if the lander had in fact moved during the perihelion passage, since its position was not fully compatible with the RF contacts obtained during FSS and after Lander wake-up.

While these two candidates formed the basis for the search, the lander search team could not discard the possibility that the actual lander may be different to these two. In that respect, the focus of the search was not to purely limit to observing the prime candidate from one direction but rather taking advantage of the different trajectories being flown, to image the Consert Ellipse region from different viewing angles from around the comet.

Already by late May 2016, the search for the lander had borne some fruit in that the prime candidate had been imaged with evidence starting to point to it being the possible lander. Images of the location showed bright reflective surfaces which could be compared with those of the lander but, unfortunately, could also be considered to be lander shaped ice patches. Without a clear identification, the search had to continue. Indeed, further "new" lander candidates had also been identified in imagery by that stage.

While the focus of the campaign based itself around the use of direct image visual analysis, other techniques were being used during the summer of 2016 to support the search. Such techniques included :

- Checking against high resolution 3D shape models on the best angles to view the prime candidate.

- Checking against 3D shape models for the best pointing during the visibility opportunity windows that were calculated by the ESA SGS and MOC teams.

- Updating the local Digital Terrain Model of the Consert ellipse region to allow better comparisons to be made, whereby placing a simulated lander into that ellipse, one could reconstruct the view of the CIVA images

- Comparing the CIVA images against the high resolution OSIRIS images taken at the different lander candidate locations to look for correlations

- Constructing a map of the locations around the prime candidate where it was visible $\&$ not visible in the imagery i.e. a line of sight map. This map could then be used to compare with the real RF \& sun illumination data from lander contacts

- Comparing RF \& power illumination visibility periods with the different lander candidates to see which ones best fitted the actual data

- Kicking off a study to perform computer based automatic analysis of images to identify lander candidates

As the orbits of the Rosetta spacecraft gradually began getting closer in the June/July \& August timeframe, the attempts to image the lander prime \& secondary candidates with even higher resolution continued.

On the $21^{\text {st }}$ July, the secondary candidate was observed and the images obtained served to discard it completely as the apparent lander structure observed from orbit turned out to be ice on the edge of a large boulder.

With the secondary candidate now discarded and the line of sight map showing a clear correlation between topography \& RF/sun illumination data, plus images showing a lander like structure hidden in the shadows, the evidence that the prime candidate was in fact Philae becoming more solid. There was however a significant problem with the location of this candidate due to the rocky terrain where it was located. The view of the candidate from Rosetta was impeded by an overhanging cliff region located on one side and a large rocky "noselike" structure on the other. On top of this, these regions also shadowed the location quite significantly during a large part of the comet day.

With the number of opportunities to get images running out as the mission started reaching its final stages, a major effort was placed in trying to take advantage of the local topography mismatches with the 3D shape model whereby the lower part of the nose rock dipped much further than the 3D shape model had modelled. It was over this lower region that attempts were made in late August to view the prime candidate. In addition, using these different viewing angles and recognising that the lander was now entering permanent shadow when Rosetta flew over the region, the intention was to attempt to see the "ice legs" previously seen in May and August images move against the rocky background thus confirming the structure there was indeed a manmade one rather than ice on the rocks.

On the $21^{\text {st }}$ August and the $24^{\text {th }}$ August, the images were still blocked by the leading edge of the rock. On the $30^{\text {th }}$ August, the leg of the lander could be seen just over the edge of the rock.

On the $2^{\text {nd }}$ September, the orbiter field of view was sufficient to view over the very front edge of the rock and high resolution images were taken. The distance to the comet was $2.7 \mathrm{~km}$ and the resolution approximately $5 \mathrm{~cm} /$ pixel. The images were taken taking advantage of the OSIRIS cameras quite wide dynamic range thus 
overexposing the location of the lander as it was now permanently in shadow when Rosetta was imaging it.

In these images the Philae lander was unambiguously identified (in the image NAC_2016-0902T19.57.55.254Z_ID10_1397549002_F22) on the $4^{\text {th }}$ September. The images taken in May through August which showed a lander like structure in poor resolution conditions could finally be confirmed to have been of the Philae lander.

It is notable that this optical determination of Philae's final position is very close (few 10 s of meters) to the Consert radar triangulation result [13] and the Lander's attitude is close to that expected earlier from the techniques outlined above $[15,16]$. Conversely, the Lander cannot have moved significantly since November 2014.

The lander search group wound up its activities during September 2016 having successfully identified the Philae lander on the comet approximately 22 months after its touchdown. The identification took place when the comet \& Philae were flying at a distance of approximately 680 million kms from the Earth.

There is no doubt that without the significant work and efforts of all teams involved in this group, the lander would not have been imaged before the Rosetta End of Mission.

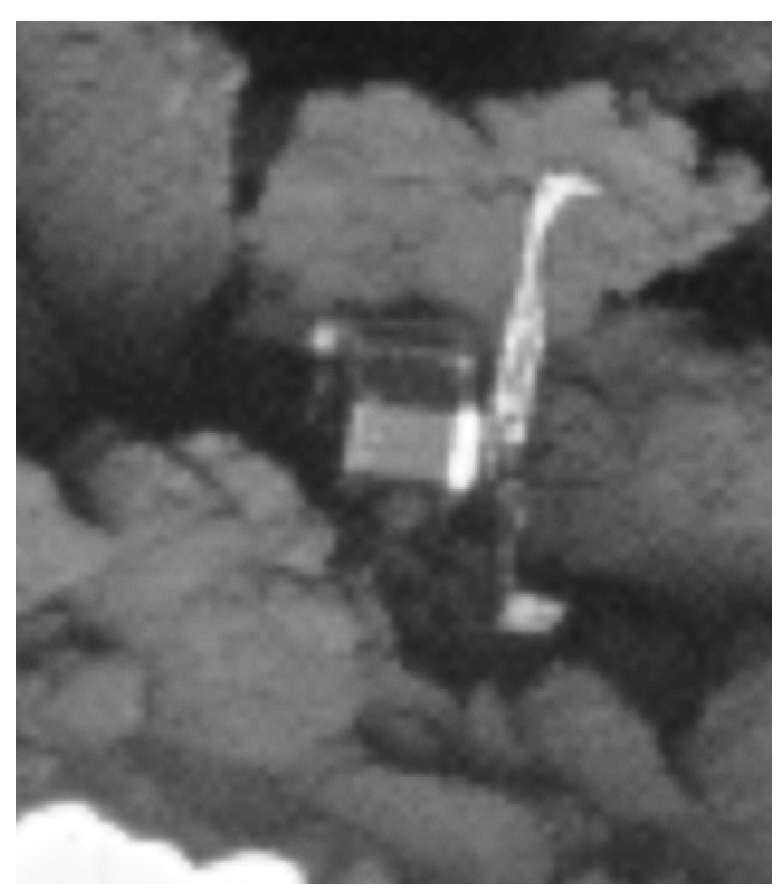

Figure 1: Close-up of the Philae lander, imaged by Rosetta's OSIRIS narrow-angle camera on 2 September 2016 from a distance of $2.7 \mathrm{~km}$. The image scale is about $5 \mathrm{~cm} /$ pixel. Philae's $1 \mathrm{~m}$-wide body and two of its three legs can be seen extended from the body. The images also provide proof of Philae's orientation. It is a zoom from a wider-scene, and has been interpolated. Copyright ESA/Rosetta/MPS for OSIRIS Team, MPS/UPD/LAM/IAA/SSO/INTA/UPM/DASP/IDA.

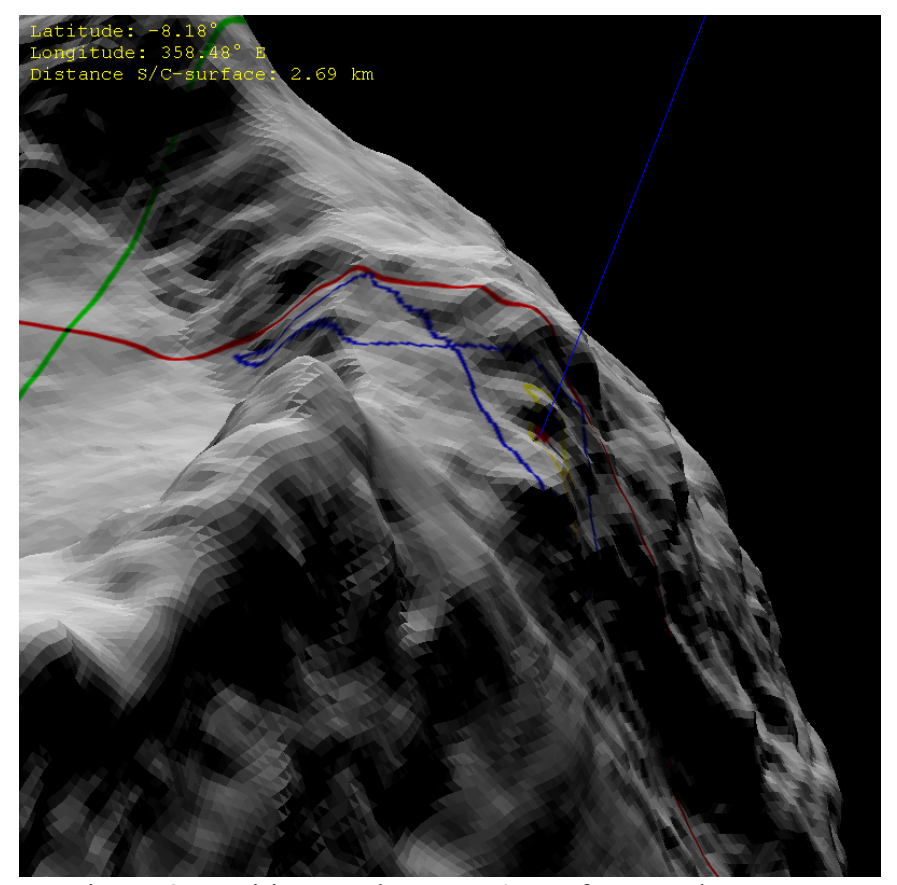

Figure 2: Position on the comet's surface. Red cross marked with blue line: „red“ candidate and practically the Lander position as imaged now. Red and green lines: equator and zero meridian. Orange/yellow/blue polygons are the $3 \sigma / 2 \sigma / 1 \sigma$-Consert ellipses [14]

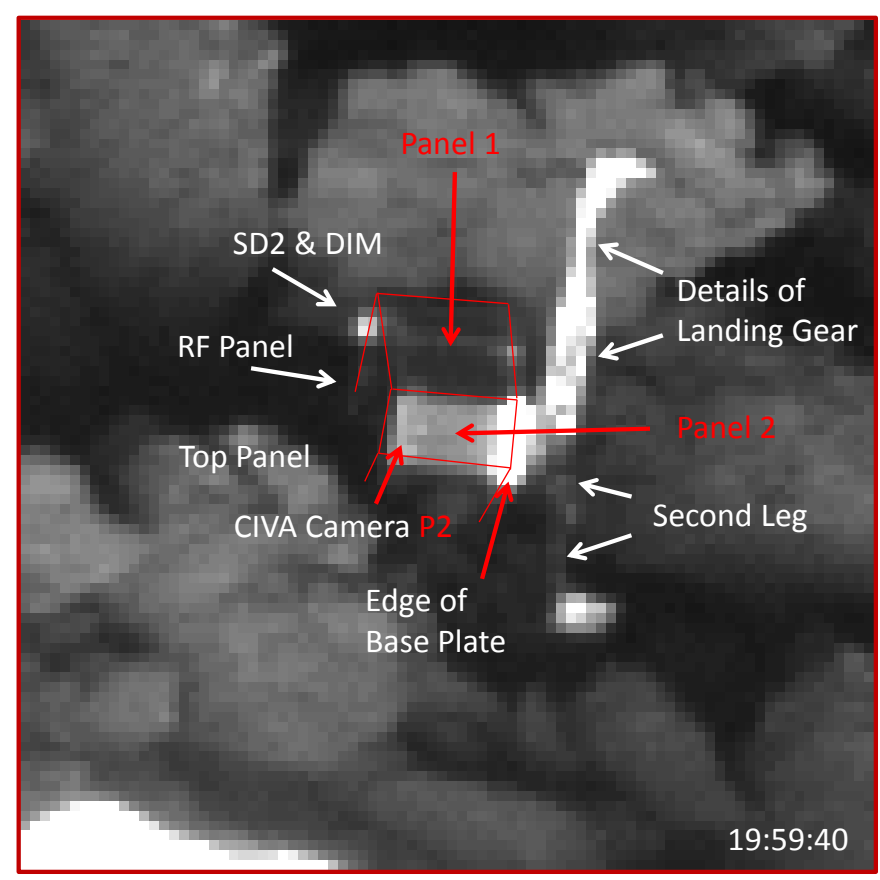

Figure 3: Interpretation of features seen in the Osiris image 


\section{LESSONS LEARNED}

The Rosetta mission, operating for about 29 months in the vicinity of a comet and Philae, the first device to actually land on a comet nucleus have provided a tremendous amount of information on the nature of comets. Consequently, future comet missions can be adapted to this environment, which is known so much better now, as compared to the time when Rosetta and Philae have been developed.

Care has to be taken regarding navigating in a dusty environment, particularly when relying on star trackers. Regarding the interaction with the surface, one of the surprising results of the Philae measurements (and the bouncing itself) is the high strength of the surface material $[3,6]$.

In addition to lessons learned about the nature of comets, there are also some aspects from a technical or programmatic point of view, where Rosetta can support the planning and designing of future missions.

Rosetta is a long term mission. It took ten years from launch until the arrival at the target comet. This raised questions regarding an appropriate knowledge management strategy [13]. Clearly, what could be learned was that documentation alone is by no means sufficient to guarantee trained and knowledgeable teams, able to quickly and efficiently react to unforeseen situations. Regular practical operations, both during periodic check-outs with the flight model but also with a representative ground reference model proved to be crucial. Consequently, key personnel needs to be engaged, even during long phases without science operations (e.g. cruise).

At this point it appears appropriate to also mention the need to continue designing and realizing missions like Rosetta or Philae in Europe without too long intervals, to make use of the unique experiences gained and the skills, which are now available within the various teams engaged with this mission.

\section{CONCLUSIONS}

Philae performed the historic first landing on a comet in November 2014. Despite bouncing, due to failures of ADS and the anchoring harpoons, the Lander came to rest and performed outstanding science. After a first sequence Philae went into hibernation from which it woke up at closer heliocentric distances and reestablished short RF links with the Orbiter after June 13.

Although, no further science operations were possible with the Lander, Rosetta continued to collect a wealth of data from orbit, which are also important to put Philae's results into context. One aspect of particular importance was the exact localization of the Lander with OSIRIS images which enables reevaluation of e.g. Consert radar data.

The data gained during the Rosetta mission with both, lander and Orbiter, will allow interpretation and analyses for the coming decades.

\section{ACKNOWLEDGEMENTS}

The authors would like to thank the teams of Rosetta and Philae for realizing the project. We would like to particularly emphasize the contributions of Dr. Helmut Rosenbauer, whose efforts were essential for the realization of the Rosetta Lander.

\section{$\underline{\text { REFERENCES }}$}

1. Glaßmeier, K.-H., Böhnhardt, H., Koschny, D., Kührt, E. and Richter I., The Rosetta Mission. Flying towards the Origins of the Solar System, Space Science Rev. 128, pp. 1-21, 2007

2. Ulamec, S., Biele, J., Blazquez, A., Cozzoni, B., Fantinati, C. et al., Rosetta Lander - Philae: landing preparations, Acta Astron., Vol. 107, pp. 79-86, 2015

3. Biele, J., Ulamec, S., Maibaum, M., Roll, R., Witte, L., et al., The landing(s) of Philae and inferences about comet surface mechanical properties. Science 349, aaa9816, 2015

4. Special Issue in Science 349, 2015

5. Biele, J. and Ulamec, S., Capabilities of Philae, the Rosetta Lander, Space Science Rev. 138, pp. 275289; 2008

6. Spohn, T., Knollenberg, J., Ball, A. J., Banaszkiewicz, M., Benkhoff, J., Grott, M., et al., Thermal and mechanical properties of the nearsurface layers of comet 67P/ChuryumovGerasimenko. Science 349, aab0464, 2015

7. Accomazzo, A., Lodiot, S. and Companys, V., Rosetta mission operations for landing, Acta Astronautica, Vol. 125, pp. 30-40, 2016

8. Ulamec, S, Fantinati, C. Maibaum, M., Geurts, K., Biele, J., Jansen, S., Küchemann, O., Cozzoni, B., Finke, F., Lommatsch, V., Moussi-Soffys, A., Delmas, C. and O'Rourke, L., Rosetta Lander Landing and operations on comet $67 \mathrm{P} / \mathrm{Churyumov-}$ Gerasimenko, Acta Astronautica, Vol. 125, pp. 8091, 2016

9. Moussi, A., Fronton, J.-F., Gaudon, P., Delmas, C., Lafaille, V., Jurado, E, Durand, J., Hallouard, D., Mangeret, M., Charpentier, A., Ulamec, S., Fantinati, C., Geurts, K., Salatti, M., Bibring, J.P. and Böhnhardt, H., The Philae Lander: Science 
planning and operations, Acta Astronautica, Vol. 125, pp. 92-104, 2016

10. Ashman, M., Barthélémy, M., O'Rourke, L., et al., Rosetta science operations in support of the Philae mission, Acta Astronautica, Vol. 125, pp. 41-64, 2016

11. Dudal, C. and Loisel, C., Rosetta-Philae RF link, challenging communications from a comet, Acta Astronautica, Vol. 125, pp. 137-148, 2016

12. Geurts, K., Fantinati, C., Ulamec, S. and Willnecker, R., Rosetta Lander: On-Comet Operations Execution and Recovery after the Unexpected Landing, $14^{\text {th }}$ International Conference on Space Operations, Conference, Daejeon, Korea, 16-20 May, 2016

13. Ulamec, S., Pätz B., Biele J., Fischer H.-H., Gaudon P., Geurts K., Krause C., Maibaum M.,
Mittag U. and Trollope E.; Knowledge Management Strategy in the Rosetta Lander Project; $3^{\text {rd }}$ International Conference on Knowledge Management, 21-23 June 2010, ESA/ESOC, Darmstadt, Germany

14. Herique, A., Y. Rogez, et al.: Philae localization from CONSERT/Rosetta measurement. Planetary and Space Science 117: 475-484, 2015.

15. Heinisch, Philip, et al., Attitude reconstruction of ROSETTA' s Lander PHILAE using two-point magnetic field observations by ROMAP and RPCMAG, Acta Astronautica 125, 174-182 (2015).

16. Remetean, E., et al. "Philae locating and science support by robotic vision techniques." Acta Astronautica 125, 161-173 (2015). 